\section{Complications during the management of pediatric refractory status epilepticus with benzodiazepine and pentobarbital infusions}

Sir,

Patten et al. in their interesting study compared complications in the management of refractory status epilepticus (RSE) treated with benzodiazepine and pentobarbital infusions. The authors addressed that children with RSE, who required pentobarbital therapy had a longer hospital stay and were more likely develop hypotension, require inotropic support, need intubation, mechanical ventilation, peripheral nutrition, and blood products. Furthermore, they were more likely to develop hypertension and movement disorder after or during weaning. ${ }^{[1]}$ I presume that these results ought to be cautiously taken owing to the presence of the following three limitations. (1) The data were taken from a single center. (2) The study period was relatively short (3 years). (3) The size of the studied cohort was small $(n=28)$. Conducting a large scale multicenter study over an extended period could better evaluate that the issue. Despite the aforementioned three limitations, the observation in Patten et al's. study ${ }^{[1]}$ on more complications associated with pentobarbital infusion compared to 
benzodiazepine infusion renders pentobarbital less recommended first-line in treating patients with RSE. This observation supports the recently published Indian consensus guidelines on the management of childhood convulsive status epilepticus ${ }^{[2]}$ and recommendations of the Italian League Against Epilepsy, ${ }_{1}^{[3]}$ which stress that the initial management of RSE should consist of a parenteral benzodiazepine (lorazepam, diazepam, or midazolam) by any route feasible and when first-line anti-epileptic drugs fail, sodium phenytoin, and phenobarbital should be used.

\section{Financial support and sponsorship}

Nil.

\section{Conflicts of interest}

There are no conflicts of interest.

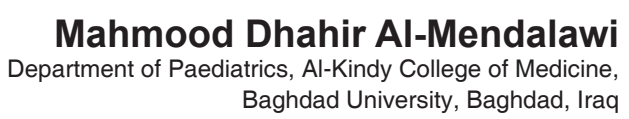

Correspondence: Prof. Mahmood Dhahir Al-Mendalawi, Department of Paediatrics, P.O. Box 55302, Baghdad Post Office, Baghdad, Iraq.

E-mail: mdalmendalawi@yahoo.com

\section{References}

1. Patten W, Naqvi SZ, Raszynski A, Totapally BR. Complications during the management of pediatric refractory status epilepticus with benzodiazepine and pentobarbital infusions. Indian J Crit Care Med 2015;19:275-7.

2. Mishra D, Sharma S, Sankhyan N, Konanki R, Kamate M, Kanhere $\mathrm{S}$, et al. Consensus guidelines on management of childhood convulsive status epilepticus. Indian Pediatr 2014;51:975-90.

3. Capovilla G, Beccaria F, Beghi E, Minicucci F, Sartori S, Vechi M. Treatment of convulsive status epilepticus in childhood: Recommendations of the Italian League Against Epilepsy. Epilepsia 2013;54 Suppl 7:23-34.

\begin{tabular}{|l|l|}
\hline \multicolumn{2}{|c|}{ Access this article online } \\
\hline Quick Response Code: & Website: \\
\hline & www.ijccm.org \\
\hline & \\
\hline
\end{tabular}

How to cite this article: Al-Mendalawi MD. Complications during the management of pediatric refractory status epilepticus with benzodiazepine and pentobarbital infusions. Indian J Crit Care Med 2015;19:431-2. 